\title{
ON THE STRUCTURAL DESIGN OF CHARACTERISTIC DECKS FOR THREE-SPAN POSTENSIONED ROAD FLYOVERS
}

\author{
FERNANDO GONZÁLEZ-VIDOSA, JULIAN ALCALÁ GONZÁLEZ \& FERRAN NAVARRO FERRER \\ Construction Engineering. Department., Universidad Politécnica Valencia, Spain
}

\begin{abstract}
This paper deals with the optimized design of two characteristic three-span road flyovers. The first characteristic sample structure is the deck of a 20-36-20 m flyover, which is typical of flyovers over double-lane, double track motorways. The second characteristic structure is the deck of a 12-17-12 m flyover, which is typical of flyovers over double-track, high-speed railways. The optimization procedure caters for the structural design of multiple voided slab decks for postensioned road flyovers. The design is encompassed by an optimized heuristic procedure. The paper shows the efficiency of a heuristic optimized design by simulated annealing (SA) method. The evaluation of solutions follows the mainframe of European and Spaniard codes of practice for structural concrete. The computation of stress resultants is carried out by an internal programming code. Road loading is in accordance to Eurocode 1 . The decks have a typical $11 \mathrm{~m}$ width. The concrete section, prestressing and the passive reinforcement are defined by 35 design variables. These variables are for the compressive strength of concrete, 5 variables for the geometry of the cross-section and 29 variables for the active and passive reinforcement. The 5 geometrical variables of the cross-section are the depth, the width of the bottom nucleus, the length of the lateral cantilevers and the thicknesses of the starting and ending parts of the cantilever. The number and diameter of the circular voids is derived from the cross-section and the active prestressing. The 20-36-20 sample results in a slab-deck of $1.55 \mathrm{~m}$ of depth and 8 tendons of 17 ASTM strands. The 12-17-12 sample results in a slab-deck of $1 \mathrm{~m}$ of depth and 6 tendons of 10 ASTM strands. Computer running times are about 3,400 seconds. It is concluded that the optimization procedure is apt and reliable for the design of postensioned slab decks.
\end{abstract}

Keywords: three-span postensioned bridges, structural design, heuristic optimization, simulated annealing.

\section{INTRODUCTION}

Engineers have sought to improve their designs since the origins of humankind. Bridges are a substantial part of transport infrastructures. Moreover, prestressed concrete bridges play a key role in the transportation systems of many countries worldwide. The traditional design of prestressed concrete bridges is based on the experience of structural engineers. A first stage in the design requires the choice of the span lengths. This stage takes into account the obstacles to be saved by the bridge, as regards roads, railways or hydraulic courses. This is the most crucial stage of the design that chooses the main characteristics of the bridge. Another stage is the choice of the bridge width, that must include space for traffic and pedestrian lanes, defenses, etc. Once the span lengths and the width are chosen, it suffices the main characteristics of the bridge. This choice is also affected by the terrain line that defines the height of the piers and abutments. As a common rule, shorter span lengths result in a lower cost of the bridge. However, this is not always the case, since the height of the piers and the abutments are a substantial part of the cost of the bridge. It is hence usually accepted that the span lengths must be between two and three times the piers height. All this definition of the bridge is the fundamental part of the bridge conception. Presently, there is no software that deals with all this conception procedures of the span lengths and the pier 
heights. All this conception procedures are presently left to the experience and the intuition of the structural engineer.

A second stage of the design process deals with the choice of the cross-section and the prestressing of the deck. It is common practice that decks of up $40 \mathrm{~m}$ of principal span are designed as slab decks (see Fig. 1). Slab decks are no longer economic starting at $50 \mathrm{~m}$ of main span. Design then moves to box-girder cross-section decks. As regards common practice, slab decks for roads are designed with depth/span ratios of about $1 / 20$ for one and two span bridges. Span/depth ratio moves to $1 / 25$ for non-determinate decks of three and more span segments. Prestressed box girder bridges for roads are usually designed with depth/span ratios of about $1 / 20$. It then follows the choice of the dimensions of the cross-section and the type of materials sanctioned by common usage. Prestressing is usually chosen by ratios of material as in similar bridges. Once the structure is defined in accordance to the experience of the engineer, it then follows the computation of stress-resultants and the passive reinforcement to comply with the list of ultimate and service limit states prescribed by the structural concrete code. The initial structural design so defined may result insufficient or excessive. The structural design is then redefined following a trial and error scheme. This design procedure leads to safe designs, but the cost of the structure is highly dependent on the experience of the structural designer. Additionally, these type of designs are not objective, since results are different according to different structural engineers in spite of adhering to the same structural codes of practice.

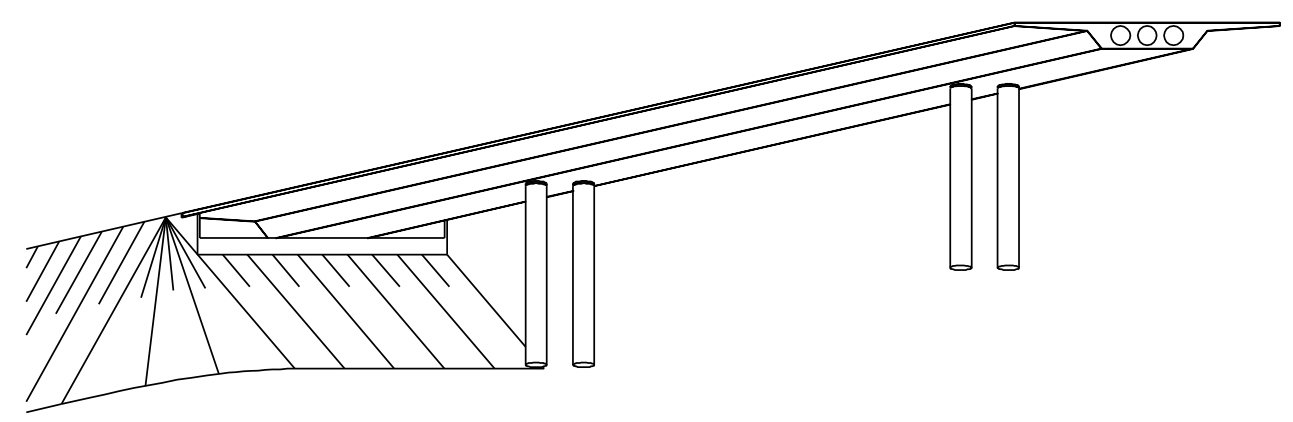

Figure 1: 3-D view of a slab-deck bridge.

Structural optimization methods are clear alternatives to designs based on experience. These methods comprise the exact methods and the heuristic methods. The exact methods are the traditional approach. They are based on the computation of optimal solutions following iterative procedures based on linear programming [1], [2]. These methods are very efficient when the number of design variables is small, but the computational costs are prohibitive when there is a high number of design variables. The second group are the heuristic methods, whose recent development is linked to the evolution of the methods based on artificial intelligence. This category includes a large number of heuristic search algorithms [3]-[6], such as the genetic algorithms, the simulated annealing, the threshold accepting, the taboo search procedure, the ant colony algorithm, etc. These methods have shown their 
success in areas well different from structural engineering [7]. These methods make use of simple algorithms, although they require an important computational effort, since they need a large number of iterations in which the objective function is evaluated and the structural constraints checked. Among the first contributions of heuristic applications to structural concrete, it is worth stating the 1992 contributions of Jenkins [8] and Rajeev and Krishnamoorthy [9]. These authors applied genetic algorithms to the optimization of the weight of the design of steel structures. Regarding the study of structural concrete, the first application appears to be the 1997 study by Coello et al. [10], who optimized concrete beams by genetic algorithms. More recently, it is important to note the studies that optimize structural concrete frames by genetic algorithms [11], [12]. In the last decade, our research group has applied the heuristic methods to the optimum design of cantilever walls, road frames, building frames, bridge piers and precast beam bridge decks [13]-[17]. The method followed in this study has developed firstly a structural evaluation module of slab-deck bridges, where cross-section dimensions, materials and passive and active reinforcement have been taken as design variables. This module computes the cost of the structures and checks all the structural constraints. The simulated annealing is then used for the design of two typical cases of three-span bridges for road construction.

\section{PROBLEM DEFINITION}

The problem of structural concrete optimization at hand consists of a problem of economic optimization. It deals with minimizing the objective function $\mathrm{F}$ in eqn (1), while satisfying the structural constraints in eqn (2)

$$
\begin{gathered}
F\left(x_{1}, x_{2}, \ldots x_{n}\right)=\sum_{i=1, r} p_{i} * m_{i}\left(x_{1}, x_{2}, \ldots, x_{n}\right), \\
g_{j}\left(x_{1}, x_{2}, \ldots \ldots x_{n}\right) \leq 0 .
\end{gathered}
$$

Note that the objective function $\mathrm{F}$ under consideration is the cost of the bridge deck, where $\mathrm{p}_{\mathrm{i}}$ are the unit costs and $\mathrm{m}_{\mathrm{i}}$ the measurements of the six units in which the construction of the deck is split. The cost function is the addition of the cost of the materials (concrete, passive and active reinforcement), plus all the entries required to evaluate the whole cost of the deck (shuttering, formwork and voids) The unit costs are given in Table 1. These prices were obtained from national contractors. The structural constraints in expression (2) are all the service limit states (SLS) and the ultimate limit states (ULS) that the structure must verify. Given the design variables, the measurement of the structure is straightforward, so that the evaluation of the cost requires little computational effort. Most of the computational effort goes in the structural verification of the structure. It is important to stress that some studies transform the problems with structural constraints into problems without structural constraints by making use of penalty functions. These penalty functions are small for light non-compliances and grow exponentially for large non-compliances. This study does not make use of penalty functions and all working solutions stay feasible, i.e. all solutions comply with the structural constraints.

Design variables considered in this study are shown in Table 2. The first five variables, which are geometrical, define the external contour of the cross-section of the slab-deck (see Fig. 2). Geometrical variables are the depth (c), the width of the base (b), the length of the lateral cantilever $(v)$ and the thickness of the cantilever at both at the starting and final ends $\left(e_{1} \mathrm{y} e_{2}\right.$ respectively). 
Table 1: Unit costs of the deck.

\begin{tabular}{|l|c|}
\hline Deck unit & Cost (euros) \\
\hline $\mathrm{m}^{3}$ shuttering & 6.010 \\
\hline $\mathrm{m}^{2}$ formwork & 30.652 \\
\hline $\mathrm{m}^{3}$ voids & 53.899 \\
\hline $\mathrm{m}^{3} \mathrm{C}-35$ concrete & 53.899 \\
\hline $\mathrm{m}^{3} \mathrm{C}-40$ concrete & 58.995 \\
\hline $\mathrm{m}^{3} \mathrm{C}-45$ concrete & 63.803 \\
\hline $\mathrm{m}^{3} \mathrm{C}-50$ concrete & 68.612 \\
\hline $\mathrm{kg} \mathrm{Y}-1860$ S7 active reinforcement & 2.404 \\
\hline $\mathrm{kg}$ B-500S passive reinforcement & 0.583 \\
\hline
\end{tabular}

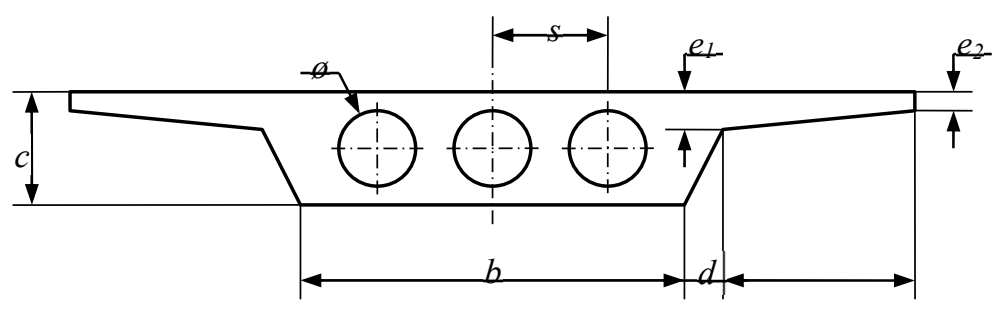

$v$

Figure 2: Geometrical variables of the cross-section of the slab-deck.

The shear and the prestressing tendons must be placed in the webs of the void cross-section. The necessary amount of prestressing may require more than a cable per web. The shear reinforcement must go together with the prestressing layout.

The depth of the cross-section is allowed to vary between 1.0 and $3.5 \mathrm{~m}$ in steps of $5 \mathrm{~cm}$. The bottom base can take any value multiple of $5 \mathrm{~cm}$ between $40 \%$ and $60 \%$ of the total width of the deck. As regards a width deck of $11 \mathrm{~m}$, the bottom base $b$ can vary between from a minimum of $4.40 \mathrm{~m}$ to a maximum of $6.60 \mathrm{~m}$. The maximum cantilever lengths $(v)$ are dependent on the bottom base $(b)$. This generates an interdependence between the $b$ and $v$ variables that could be a drawback, since large cantilever lengths may result incompatible with some values of the bottom width (the sum of the cantilever lengths plus the bottom width cannot exceed the total width of the deck). Variable $v$ has been replaced by variable $d$ in Fig. 2 , so as to suppress this interdependence. This lateral web variable $d$ can vary between 0 and $0.55 \mathrm{~m}$, i.e. up to $5 \%$ of the total width of the cross section. Thickness of the cantilever $e_{1}$ can vary between $0.25 \mathrm{~m}$ and $0.45 \mathrm{~m}$ in steps of $2.5 \mathrm{~cm}$. The free edge thickness of the cantilever $e_{2}$ can only take the values of $0.15,0.20$ and $0.25 \mathrm{~m}$. Voids considered are always circular. Their placing in the cross-section only depends on the external cross-section. This explains why there are no void variables in Table 2 . The procedure for placing voids is as follows. Firstly, the diameter of the voids ( $\varnothing)$ are chosen as a function of the depth of the cross section. It then follows a minimum web width for the space between voids. Finally, the number of voids is the maximum number that can be fitted in the section. Void spacing $(s)$ is determined so as the lateral webs measure the same as the internal webs, as shown in Fig. 3. 
Table 2: Design variables of the problem.

\begin{tabular}{|c|c|}
\hline Description & Variable \\
\hline \multicolumn{2}{|l|}{ Concrete variables } \\
\hline Depth of the deck & $c$ \\
\hline Base width & $b$ \\
\hline Cantilever length & $v$ \\
\hline Cantilever starting thickness & $e_{1}$ \\
\hline Cantilever edge thickness & $e_{2}$ \\
\hline Concrete grade & $H$ \\
\hline \multicolumn{2}{|l|}{ Prestressing variables } \\
\hline Total number of strands & $N_{T}$ \\
\hline \multicolumn{2}{|l|}{ Longitudinal passive reinforcement variables } \\
\hline Bottom base reinforcement & $A l_{1}$ \\
\hline Nucleus base top reinforcement & $A l_{2}$ \\
\hline Top cantilever reinforcement & $\mathrm{Al}_{3}$ \\
\hline Bottom cantilever reinforcement & $\mathrm{Al}_{4}$ \\
\hline Lateral web base reinforcement & $A l_{5}$ \\
\hline Additional bottom reinforcement & $A l_{l i}$ \\
\hline Additional nucleus top reinforcement & $A l_{2 i}$ \\
\hline Additional lateral web reinforcement & $A l_{5 i}$ \\
\hline \multicolumn{2}{|l|}{ Transverse passive reinforcement variables } \\
\hline Basic spacing modulation & mod \\
\hline Contour reinforcement of the nucleus in zone $\mathrm{j}$ & $A t_{1 j}$ \\
\hline Top transverse reinforcement in zone $\mathrm{j}$ & $A t_{2 j}$ \\
\hline Bottom cantilever reinforcement in zone $\mathrm{j}$ & $A t_{3 j}$ \\
\hline Shear transverse reinforcement in zone $\mathrm{j}$ & $A t_{4 j}$ \\
\hline
\end{tabular}

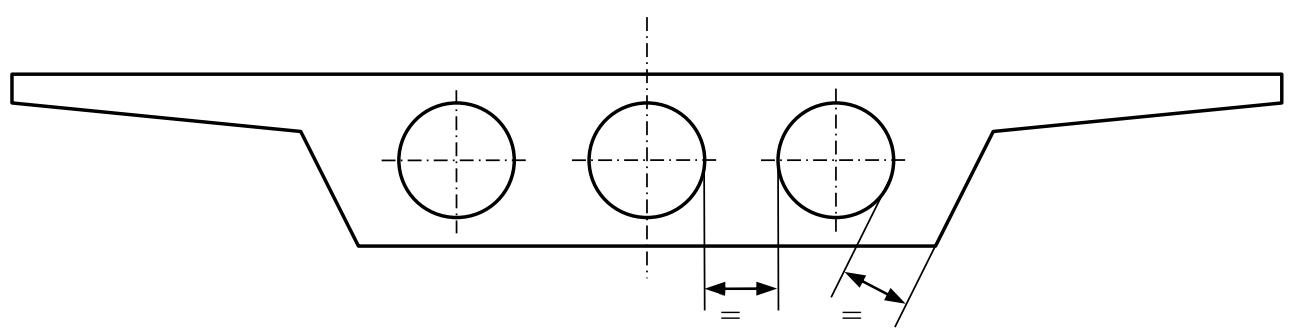

Figure 3: Void spacing criterion. 
Void diameter is set to $0.60 \mathrm{~m}$ for slab depths of $1.00 \mathrm{~m}$ and to $1.40 \mathrm{~m}$ for slab depths larger than $2.00 \mathrm{~m}$. The minimum web width is set to $0.3 \mathrm{~m}$ for slab depths of $1.00 \mathrm{~m}$ and to $0.5 \mathrm{~m}$ for slab depths larger than $2.00 \mathrm{~m}$. The void diameter and the web width are linearly interpolated for intermediate cases. Next variable is the concrete grade $H$. This value corresponds to the cylinder compressive strength at 28 days. $(35,40,45,50 \mathrm{MPa})$. The procedure does not allow the $30 \mathrm{MPa}$ grade since it has little rigidity for the commonly used prestressing sequences.

Prestressing is kept constant along the whole deck. There is only one design variable, which is the number of strands $\left(N_{T}\right)$. All the strands are of the type Y-1860 S7 of seven filaments and $15.7 \mathrm{~mm}$ of diameter. The initial prestressing force is taken as $75 \%$ of the ultimate stress of the strand, which is $f_{p u}=260.7 \mathrm{kN}$. There are limits to the minimum and the maximum amount of prestressing. The limits are such that the number of strands $N_{T}$ must vary between $5 \mathrm{~kg}$ and $50 \mathrm{~kg}$ per square meter of structure (Note that typical ratios vary generally from 10 y $20 \mathrm{~kg} / \mathrm{m}^{2}$ ). The number of strands will range between 49 and 499 for a strand weight of $1.102 \mathrm{~kg} / \mathrm{m}$ and a deck width of $11 \mathrm{~m}$. The distribution of strands in the cross-section requires some provisions. All tendons in the section are equal, which implies that the number of strands $N_{T}$ must be a multiple of the number of tendons. For voided sections, the number of tendons must be proportional to the number of webs, which causes a dependence of prestressing and geometrical variables, since the number of webs depends on the external cross-section as explained above. This dependence is solved by making use of two variables instead of only one variable. The first variable is the number of strands $N_{T 0}$ used in the optimization programming techniques; and the second variable is $N_{\text {Treal }}$, which is the number of strands adopted so as to adapt to the web geometry of cross-section of the deck. The first variable is used as regards programming the optimization techniques; and the second variable is used for structural checking of the deck and to evaluate the objective function. $N_{\text {Treal }}$ is obtained from $N_{T 0}$ as follows. It is firstly obtained the number of strands in each tendon assuming that their number is equal to the number of webs. Should the number of strands exceed 31, then the number of tendons per web in incremented in 1 as many times so as to have tendons with no more than 31 strands. Nevertheless, the number of tendons per web should be such that there is enough space in the depth for the anchoring plates. If there is no more space for additional anchoring plates, then the number of tendons is kept with 31 strands. Once the number of strands per tendon is set, the diameter of the duct can be chosen. The diameter of the duct and the size of the anchoring plates have been taken from commercial prestressing catalogues. These values are shown in Table 3.

The rest of the design variables are those that define the passive reinforcement. Passive reinforcement is always of the type B-500S (500 MPa of yielding stress). The passive reinforcement is made of longitudinal and transversal bars. Longitudinal reinforcement includes a base reinforcement that it is common to the whole deck, plus additional bars for different zones of the deck for flexure and torsion. The reinforcement layout is based on five types of bars, as shown in Fig. 4. These bars are the bottom nucleus bars $\left(A l_{1}\right)$, the top nucleus bars $\left(A l_{2}\right)$, the top cantilever bars $\left(A l_{3}\right)$, the bottom cantilever bars $\left(A l_{4}\right)$ and the lateral web bars $\left(A l_{5}\right)$. Longitudinal bars are defined by their diameters and the number of bars per linear meter. The minimum amount is 4 bars of $6 \mathrm{~mm}$ of diameter (spacing of $25 \mathrm{~cm}$ ). The maximum amount is 10 bars of $32 \mathrm{~mm}$ of diameter (spacing $10 \mathrm{~cm}$ ). All the intermediate number of bars and diameters are allowed.

Transversal bars are dealt with in a different manner. The variables considered are shown in Fig. 5. Transversal bars consist of nucleus contour bar $\left(A t_{1}\right)$, a top transverse bar $\left(A t_{2}\right)$, a bottom cantilever bar $\left(A t_{3}\right)$ and shear stirrups in all the section webs $\left(A t_{4}\right)$. There are zones of reinforcement of $70 \%$ of the span and $15 \%$ of the spans above the pier sections. Each of these 
bars is defined by its diameter (from 6 to $32 \mathrm{~mm}$ ) and a spacing that can only take the values of $10 \mathrm{~cm}, 12.5 \mathrm{~cm}$ and $15 \mathrm{~cm}$ and their double values. The spacing of the transversal bars is common to the whole deck. This is achieved by means of a variable called modulation ( $\mathrm{mod}$ ) that defines which of the three possible spacing is used. The number of stirrups is equal to the number of webs of the cross-section. All variables are for halve the deck since symmetry of the deck is assumed. The reinforcement of the transverse beams in abutments and pier sections, as well as the reinforcement of the anchoring plates, are not considered, since they play a minor role in the optimization of the deck.

Table 3: Duct diameters and size of anchoring plates.

\begin{tabular}{|c|c|c|}
\hline $\begin{array}{c}\text { Strands per } \\
\text { tendon }\end{array}$ & $\begin{array}{c}\varnothing \text { duct } \\
\mathrm{mm}\end{array}$ & $\begin{array}{c}\text { Plate size } \\
\mathrm{mm}^{2}\end{array}$ \\
\hline 3 & 42 & $140 \times 140$ \\
\hline 4 & 51 & $180 \times 180$ \\
\hline $5-6$ & 63 & $180 \times 180$ \\
\hline 7 & 63 & $200 \times 200$ \\
\hline 8 & 81 & $200 \times 200$ \\
\hline 9 & 81 & $240 \times 240$ \\
\hline $10-11$ & 90 & $240 \times 240$ \\
\hline $12-14$ & 90 & $270 \times 270$ \\
\hline 15 & 90 & $300 \times 300$ \\
\hline $16-18$ & 100 & $300 \times 300$ \\
\hline 19 & 100 & $340 \times 340$ \\
\hline $20-23$ & 110 & $340 \times 340$ \\
\hline $24-27$ & 110 & $380 \times 380$ \\
\hline $28-30$ & 120 & $380 \times 380$ \\
\hline 31 & 120 & $430 \times 430$ \\
\hline
\end{tabular}

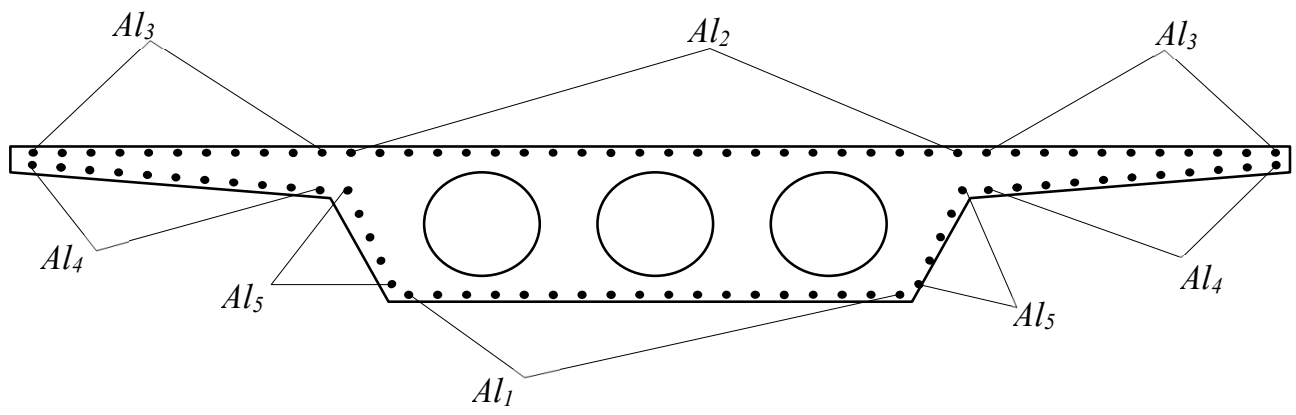

Figure 4: Longitudinal bars set-up. 


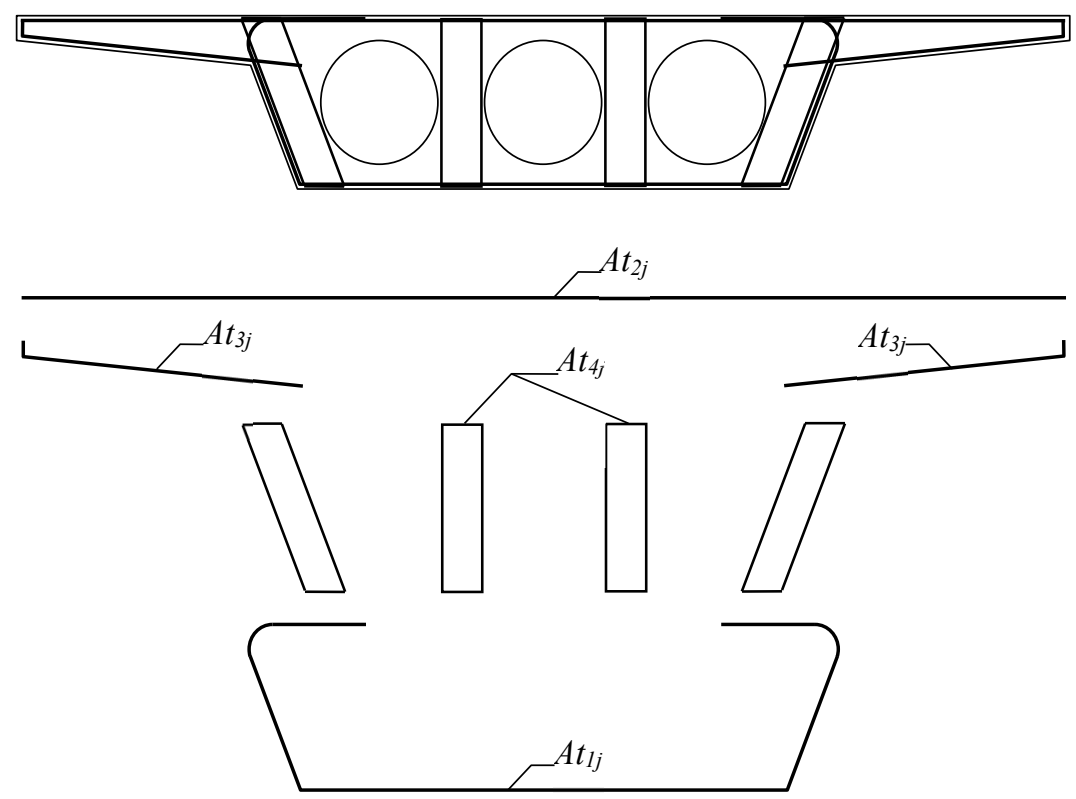

Figure 5: Transverse bars set-up.

\section{SOLVING METHOD}

The solving method used in this research is the simulated annealing (SA). This method is considered a metaheuristic, since it is capable of solving difficult problems of combinatorial optimization and it has proved applicable to problems of different nature. This search method was originally proposed by Kirkpatrick et al. [18] for the design of electronic circuits. It is worth noting that the choice of the best metaheuristic for the problem at hand is outside the scope of this paper. The SA algorithm is based on the analogy of crystal forming from high temperature melted masses allowed to cool slowly. The melted mass goes from one crystal configuration to another as the mass cools. At high temperatures transitory melted configurations of higher energy than the previous one can form. However, as the mass cools, it decreases the probability of new configurations of higher energy. The process is governed by the Boltzmann expression $e^{(-\Delta E / k b T)}$, where $\Delta E$ is the increment of energy of the new configuration; $T$ is the temperature; and $k_{b}$ is the constant of Boltzmann. The algorithm starts with a feasible solution generated at random and a very high temperature. The initial solution is then modified by a small random change of the design variables. The new solution is evaluated in terms of cost. The procedure only accepts new solutions that are feasible, i.e. solution that comply with the structural constraints. Solutions of grater cost are only accepted when a random number between 0 and 1 is smaller than the expression $e^{(-\Delta E / T)}$, where $\Delta E$ is the cost increment and $\mathrm{T}$ is the current temperature. The working solution is checked in terms of structural constraints and, if it is feasible, it is accepted as the new working solution. The initial temperature is decreased geometrically $(T=k T)$ by means of a cooling coefficient $\mathrm{k}$. A number of iteration called Markov chain is performed at each temperature stage. The algorithm stops when the temperature is a small percentage of the initial temperature (typically $0.02 \%$ ). The SA algorithm is capable of surpassing local optimal solutions at 
high-medium temperatures and it gradually converges as the temperature goes to zero. The SA algorithm is calibrated for an initial temperature, the length of the Markov chains and the cooling coefficient.

Fig. 6 shows a typical evolution of cost versus iterations till optimal results are achieved. As regards the initial solution, it was attempted to generate feasible solutions totally at random. However, it was observed that the percentage of feasible random solutions was so low that the time consumed in generating a single random solution was prohibitive. This problem was solved by the development of an intelligent algorithm that repaired the prestressing design of randomly generated solutions. This intelligent algorithm will be the object of future publications. This repairing algorithm is repeated until a feasible initial solution is generated. The initial solution is then successively modified by small random changes of the design variables. Every small change of the design variables is called a move. Typically, up to 7 variables are changed in every move. There were tested changes of less and more than 7 variables, but the procedure proved to be less efficient. It is important to stress that the simplest version would only change one variable in each move, but it has become common practice that is more effective to alter several variable in each go, although the optimum number requires a calibration and varies from one case study to another. Variables are discrete and they are modified in plus or minus one of their table of possible values. The initial temperature was adjusted following the method proposed by Medina [19]. This method first determines whether the percentage of accepted solutions of higher energy is outside the range of $20 \%$ to $40 \%$. If such percentage is larger than $40 \%$, then the initial temperature is halved. If the percentage of acceptances is smaller than $20 \%$ then the temperature is doubled. The first initial temperature was adjusted as 1/200 the cost of the initial solution. Cooling coefficients of $0.80,0.85$ y 0.90 were tried; and finally a cooling coefficient of 0.80 was adopted. Several lengths of Markov chains were also tested and it was finally adopted a value of 20,000 iterations. The algorithm stops when the temperature is smaller than $0.02 \%$ the value of the initial temperature and when there have been two Markov chains without any improvement. The algorithm is executed 7 times so as to obtain minimum and maximum values, together with the standard deviation of the results. This number of 7 runs was considered sufficient for a precision of $1 \%$ when compared to the results for 99 runs. It is important to note that the global optimum is not found, since no heuristic procedure guarantees such achievement. Nevertheless, the results shown in section 4 are of very good quality according to the authors' structural engineering experience.

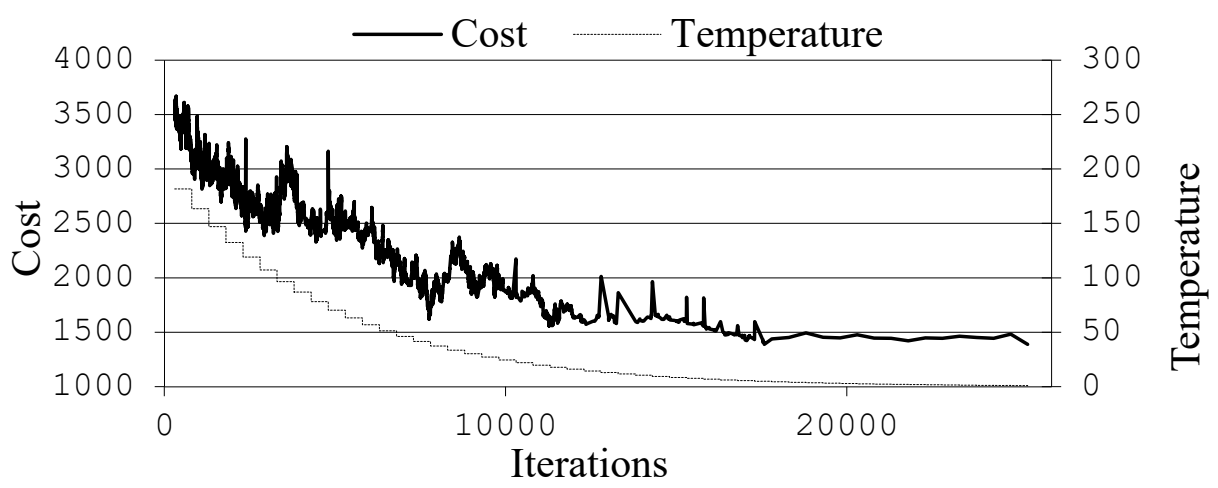

Figure 6: Example of SA solving trajectory. 


\section{NUMERICAL EXAMPLES}

The present numerical optimization model has been applied to two three-span decks of $11 \mathrm{~m}$ of width. The first example is a 20-36-20 m of span lengths typical of motorway flyovers. The second example is a 12-17-12 m of span lengths typical of flyovers over high-speed railways lines. The structural concrete code considered for checking the structural constraints is Eurocode 2. The code considered for loading is Eurocode 1. The dead loads considered are $44 \mathrm{kN} / \mathrm{m}$. The environmental exposure considered is XC4. The integration of cracked sections is performed with the Gauss-Legendre quadrature proposed by Bonet et al. [20]. The main results for the seven computer runs the first example are shown in Table 4. This table details the case, the cost in euros of the deck, the slab depth, the number of strands, the number of voids, the width of the bottom of the deck, the cantilever length and the thicknesses of the cantilever at both ends. Concrete grade is C-35 in all cases. The best result is the corresponding to run 4. This result has a cost of 191.70 euros $/ \mathrm{m}^{2}$. The depth of the deck is $1.55 \mathrm{~m}$, which gives a depth/span ratio of $1 / 23.23$. The prestressing is composed by 8 tendons of 17T0.6", which gives a ratio of $13.62 \mathrm{~kg} / \mathrm{m}^{2}$. The measurement of passive reinforcement is $36,531 \mathrm{~kg}\left(43.02 \mathrm{~kg} / \mathrm{m}^{2}\right)$. The ratio of longitudinal reinforcement is $14.11 \mathrm{~kg} / \mathrm{m}^{2}$. The ratio of transverse reinforcement is $28.91 \mathrm{~kg} / \mathrm{m}^{2}$. The bottom width is $4,400 \mathrm{~mm}$ and the cantilever length is $2,800 \mathrm{~mm}$. The thicknesses of the cantilever edges are 150 and $325 \mathrm{~mm}$. Note that the worst result has a cost of 166,695 euros (case 7), which deviates $2.4 \%$ from the best result. Hence, It is observed that results are pretty grouped.

Table 4: Results for the 20-36-20 deck.

\begin{tabular}{|c|c|c|c|c|c|c|c|c|}
\hline Run & $\begin{array}{c}\text { Cost } \\
(\text { euros })\end{array}$ & $\begin{array}{c}\mathrm{c} \\
(\mathrm{mm})\end{array}$ & $\begin{array}{c}\text { Prestressing } \\
(\text { tendons })\end{array}$ & $\begin{array}{c}\text { Voids } \\
(\mathrm{mm})\end{array}$ & $\begin{array}{c}\mathrm{b} \\
(\mathrm{mm})\end{array}$ & $\begin{array}{c}\mathrm{v} \\
(\mathrm{mm})\end{array}$ & $\begin{array}{c}\mathrm{e}_{1} \\
(\mathrm{~mm})\end{array}$ & $\begin{array}{c}\mathrm{e}_{2} \\
(\mathrm{~mm})\end{array}$ \\
\hline 1 & 162,928 & 1450 & $12 \times 12$ & $3 \times 960$ & 4400 & 2925 & 400 & 150 \\
\hline 2 & 164,045 & 1450 & $12 \times 12$ & $3 \times 960$ & 4450 & 2775 & 375 & 150 \\
\hline 3 & 164,476 & 1550 & $12 \times 11$ & $3 \times 1040$ & 4400 & 2825 & 350 & 150 \\
\hline 4 & 162,787 & 1550 & $8 \times 17$ & $3 \times 1040$ & 4400 & 2800 & 325 & 150 \\
\hline 5 & 163,299 & 1450 & $12 \times 12$ & $3 \times 960$ & 4400 & 2800 & 375 & 150 \\
\hline 6 & 163,605 & 1450 & $12 \times 12$ & $3 \times 960$ & 4400 & 2925 & 400 & 150 \\
\hline 7 & 166,695 & 1350 & $4 \times 30$ & $3 \times 880$ & 4950 & 2625 & 375 & 150 \\
\hline
\end{tabular}

The main results for the seven computer runs of the second example are shown in Table 5 (12-17-12 m span lengths). Concrete grade is again C-35 in all cases. The best result is the corresponding to case 1 . This result has a cost of 156.17 euros $/ \mathrm{m}^{2}$. The depth of the deck is $1.00 \mathrm{~m}$, which gives a depth/span ratio of $1 / 17$. The prestressing is composed by 6 tendons of $10 \mathrm{~T} 0.6$ ", which gives a ratio of $6.01 \mathrm{~kg} / \mathrm{m}^{2}$. The measurement of passive reinforcement is $20,831 \mathrm{~kg}\left(44.88 \mathrm{~kg} / \mathrm{m}^{2}\right)$. The ratio of longitudinal reinforcement is $17.38 \mathrm{~kg} / \mathrm{m}^{2}$. The ratio of transverse reinforcement is $27.50 \mathrm{~kg} / \mathrm{m}^{2}$. The bottom width is $5,000 \mathrm{~mm}$ and the cantilever length is $2,525 \mathrm{~mm}$. The thicknesses of the cantilever edges are 150 and $300 \mathrm{~mm}$. Note that the worst result has a cost of 73,531 euros (case 7 again), which deviates $1.4 \%$ from the best result. Hence, It is again observed that the scatter of the results is small. Computer running times are about 3,400 seconds for both examples. The processor is an Intel Core TMi5 - 7400 CPU $3.6 \mathrm{GHz}$. 
Table 5: Results for the 12-17-12 deck.

\begin{tabular}{|c|c|c|c|c|c|c|c|c|}
\hline Run & $\begin{array}{c}\text { Cost } \\
(\text { euros })\end{array}$ & $\begin{array}{c}\mathrm{c} \\
(\mathrm{mm})\end{array}$ & $\begin{array}{c}\text { Prestressing } \\
(\text { tendons })\end{array}$ & $\begin{array}{c}\text { Voids } \\
(\mathrm{mm})\end{array}$ & $\begin{array}{c}\mathrm{b} \\
(\mathrm{mm})\end{array}$ & $\begin{array}{c}\mathrm{v} \\
(\mathrm{mm})\end{array}$ & $\begin{array}{c}\mathrm{e}_{1} \\
(\mathrm{~mm})\end{array}$ & $\begin{array}{c}\mathrm{e}_{2} \\
(\mathrm{~mm})\end{array}$ \\
\hline 1 & 72,494 & 1000 & $6 \times 10$ & $5 \times 600$ & 5000 & 2525 & 300 & 150 \\
\hline 2 & 72,872 & 1000 & $6 \times 10$ & $5 \times 600$ & 4950 & 2475 & 300 & 150 \\
\hline 3 & 72,840 & 1000 & $6 \times 10$ & $5 \times 600$ & 4900 & 2525 & 300 & 150 \\
\hline 4 & 72,901 & 1050 & $5 \times 12$ & $4 \times 640$ & 4500 & 2700 & 325 & 150 \\
\hline 5 & 72,995 & 1000 & $6 \times 10$ & $5 \times 600$ & 4650 & 2625 & 325 & 150 \\
\hline 6 & 72,512 & 1000 & $6 \times 10$ & $5 \times 600$ & 4450 & 2775 & 350 & 150 \\
\hline 7 & 73,531 & 1000 & $6 \times 10$ & $5 \times 600$ & 4450 & 2725 & 375 & 150 \\
\hline
\end{tabular}

5 CONCLUDING REMARKS

It has been presented a model for the optimized design of multiple span slab-decks. The model includes 35 design variables that cover the type of concrete, the geometry of the cross-section, the prestressing tendons and the longitudinal and transverse passive reinforcement. The algorithm used is the simulated annealing. Decks are checked against the limit states of Eurocode 2 and the actions considered are those in Eurocode 1. The model has been applied to two characteristic three span decks of 20-26-20 m and 12-17-12 m of $11 \mathrm{~m}$ of width, $44 \mathrm{kN} / \mathrm{m}$ of dead loads and environmental exposure XC4. Results for the 20-36-20 example indicate a depth/span ratio of $1 / 23.23$ and an active and passive amount of reinforcement of $13.62 \mathrm{~kg} / \mathrm{m}^{2}$ and $43.02 \mathrm{~kg} / \mathrm{m}^{2}$, respectively. Results for the 12-17-12 example indicate a depth/span ratio of $1 / 17$ and an active and passive amount of reinforcement of $6.01 \mathrm{~kg} / \mathrm{m}^{2}$ and $44.88 \mathrm{~kg} / \mathrm{m}^{2}$, respectively.

\section{REFERENCES}

[1] Hernandez, S. \& Fontan, A., Practical Applications of Design Optimization, WIT Press: Southampton, 2002.

[2] Fletcher, R., Practical Methods of Optimization, Wiley: Chichester, 2001.

[3] Jones, T., Artificial Intelligence Application Programming. Charles River Media: Hingham, 2003.

[4] Holland, J.H., Adaptation in Natural and Artificial Systems, University of Michigan Press: Ann Arbor, 1975.

[5] Goldberg, D.E., Genetic Algorithms in Search, Optimization and Machine Learning, Addison-Wesley, 1989.

[6] Glover, F. \& Laguna, M., Tabu Search, Kluwer Academic Publishers: Boston, 1997.

[7] Yepes, V. \& Medina, J.R., Economic heuristic optimization for heterogeneous fleet VRPHESTW. ASCE Journal of Transportation Engineering, 132(4), pp. 303-311, 2006.

[8] Jenkins, W.M., Plane frame optimum design environment based on genetic algorithm. ASCE Journal of Structural Engineering, 118(11), pp. 3103-3112, 1992.

[9] Rajeev, S. \& Krisnamoorthy, C.S., Discrete optimization of structures using genetic algorithms. ASCE Journal of Structural Engineering, 118(5), pp. 1233-1250, 1992.

[10] Coello, C.A., Christiansen, A.D. \& Santos, F., A simple genetic algorithm for the design of reinforced concrete beams. Engineering with Computers, 13, pp. 185-196, 1997. 
[11] Lee, C. \& Ahn, J., Flexural design reinforced concrete frames by genetic algorithm. ASCE Journal of Structural Engineering, 129(6), pp. 762-774, 2003.

[12] Camp, C.V., Pezeshk, S. \& Hansson, H., Flexural design reinforced concrete frames using a genetic algorithm. ASCE Journal of Structural Engineering, 129(1), pp. 105$115,2003$.

[13] Yepes, V., Alcalá, J., Perea, C. \& González-Vidosa, F., A parametric study of optimum earth retaining walls by simulated annealing. Engineering Structures, 30(3), pp. 821830, 2008.

[14] Perea, C., Alcalá, J., Yepes, V., González-Vidosa, F. \& Hospitaler, A., Design of reinforced concrete bridge frames by heuristic optimization. Advances in Engineering Software, 39(8), pp. 676-688, 2008.

[15] Payá-Zaforteza, I., Yepes, V., González-Vidosa, F. \& Hospitaler, A., Multiobjective optimization of reinforced concrete building frames by simulated annealing. Computer-Aided Civil and Infrastructure Engineering, 23(8), pp. 575 -589, 2008.

[16] Martinez, F.J., González-Vidosa, F., Hospitaler, A. \& Yepes, V., Heuristic optimization of RC bridge piers with rectangular hollow sections. Computers and Structures, 88(5-6), pp. 375-386, 2010.

[17] Martí, J.V., González-Vidosa, F., Yepes, V. \& Alcalá, J., Design of prestressed concrete precast road bridges with hybrid simulated annealing. Engineering Structures, 48, pp. 342-352, 2013.

[18] Kirkpatrick, S., Gelatt, C.D. \& Vecchi, M.P., Optimization by simulated annealing. Science, 220(4598), pp. 671-680, 1983.

[19] Medina, J.R., Estimation of incident and reflected waves using simulated annealing. ASCE Journal of Waterway, Port, Coastal and Ocean Engineering, 127(4), pp. 213221, 2001.

[20] Bonet, J.L., Romero, M.L., Miguel, P.F. \& Fernández, M.A., A fast stress integration algorithm for reinforced concrete sections with axial loads and biaxial bending. Computers \& Structures, 82, pp. 213-225, 2004. 